\title{
Is there a Link between Physical, Cognitive and Fear of Falls among Elderly with Diabetes Mellitus?
}

\author{
Azliyana Azizan, Asilah Anum, Amiera Alias \\ Faculty of Health Sciences, \\ Universiti Teknologi MARA, Malaysia \\ azliyana9338@puncakalam.uitm.edu.my, asilahrustami@gmail.com, nooramiera.alias@gmail.com
}

\begin{abstract}
Imbalance and general weakness are amongst the most common impairments in the elderly and put them at a significantly higher risk of falling. Therefore, this study aims to compare the physical and cognitive functions towards fear of falls among 80 community-dwelling elders with and without diabetes mellitus. The results revealed that there was a decline in cognitive functions, reduced in physical function and high risk of falls among the elderly with diabetes. In conclusion, balance and resistance training need to be included in the daily exercise regime to reduce the risk of falls in the elderly, especially those with diabetes.
\end{abstract}

Keywords: Cognitive; Elderly; Fear of falls; Physical

eISSN 2514-7528 @ 2019. The Authors. Published for AMER ABRA cE-Bs by e-International Publishing House, Ltd., UK. This is an open-access article under the CC BY-NC-ND license (http://creativecommons.org/licenses/bync-nd/4.0/). Peer-review under responsibility of AMER (Association of Malaysian Environment-Behaviour Researchers), ABRA (Association of Behavioural Researchers on Asians) and CE-Bs (Centre for EnvironmentBehaviour Studies), Faculty of Architecture, Planning \& Surveying, Universiti Teknologi MARA, Malaysia. DOI: https://doi.org/10.21834/jabs.v4i13.333 


\subsection{Introduction}

Falls among the elderly are the most public health concern, and it can cause physical and psychological dysfunctions which include injuries, hospitalization, and institutionalization (Reelick, van lersel, Kessels, \& Olde Rikkert, 2009), decline muscle power and poor balance performance (Schinkel-Ivy, Inness \& Mansfield, 2015) as well increase fear of falls (FOF) (Jung, 2008). Thus, this could cause physical inactivity and a decline in their overall quality of life (Reelick et al., 2009; Toebes, Hoozemans, Furrer, Dekker,\& Van Dieën, 2015).

Three significant predictors that related to the incidence of falls in the elderly are balance abilities, fear of fall and lower limb weakness. The previous study showed that ability to sustain balance while in movements such as performing daily or multitasking activities are declined with age (Ghanavati, Shaterzadeh Yazdi, Goharpey, \& Arastoo, 2012; Reelick et al., 2009). Reduce balance control among the elderly contributed to a reduction in walking velocity and step width as well as a decrease in the movement of the lower limb joints. Therefore, this may cause a gait problem and increased the risk of falls (Lim, Kim, Noh, Yoo, \& Moon, 2014). An elderly who experienced falls may develop fear towards recurrent falls and may cause psychological syndrome. Depressingly, it will lead decline in quality of life, frailer and develop muscle atrophy (Tander et al.,2016). Also, several falls may cause a low confidence level and anxiety towards the elderly thus creates an unsafe walking pattern and contribute to a high risk of fall.

\subsection{Literature Review}

Fear is define as emotion created by particular designs of threat-related stimuli, and in turn causing specific patterns of adaptive behaviors to avoid or cope that risk (Adolps, 2013). A review by Adolph (2013) stated that fear and anxiety is diverse as fear is adaptive, but temporary state caused by an opposition with a threatening stimulus. Meanwhile, it is more of a tonic state related to guess and alertness. Besides, a study by Gross and Canteras (2012) revealed that there is a variety of fear circuit tangled with fear of pain, predators and hostile conspecifics occur. Therefore, all of this evidence supports the concept of the fear itself.

Commonly the elderly with FOF is having many histories of falls and poor health status. Malini, Lourenço, and Lopes (2016) revealed that positive increment on the prevalence of FOF among the elderly population. The results stated that diabetic group scores low mFES than the non-diabetic group. The diabetic elderly tend to have inadequate glycaemic control which leads to a progressive decline of sensory nerve fibers in the somatosensory system (Tander et al., 2016). Diabetic people need to reduce their anxiety and FOF during activities to maintain balance and avoid falls (Hewston \& Deshpande, 2018).

Furthermore, this will put an extra problem towards them. FOF is associated with the period of diagnosis of diabetes which also related to previous study ( $P$ \& S, 2017; Tander et al., 2016) and in this present study support to this. In the future, diabetes will cause many complications such as peripheral neuropathy (Nisar et al., 2015), and reduced psychological status among elderly (Saedi, Gheini, Faiz \& Arami, 2016). According to Giacco \& Brownlee 
(2010), the long-term hyperglycemia cause changes in the brain structure which affect cognitive and increase the risk of anxiety and fear of falls among the elderly with diabetes.

\subsection{Methodology}

\subsection{Study area}

The study is done in a community area which was in Kampung Bukit Cherakah, Kuala Selangor, Malaysia.

\subsection{Study subject and sample selection}

A total of eighty elderly participants above the age of sixty years were recruited via crosssectional study and were divided into two groups: 40 diabetic and 40 non-diabetic subjects. Written consent has been given to all the subject before starting the measurements. The subjects were screened for eligibility. The inclusion criteria including the age of 60 years and above, able to tolerate and understand instructions and independent. The exclusion criteria are if they had a neurological disorder that influenced their gait, chronic respiratory and cardiac disease, had severe hearing and visual impairment and diagnosed with severe cognitive impairment by a neurologist and unable to follow the command. All subjects were being examined about their demographic and medical status and were asked on the history of falls, the level of FOF and number of falls in the past 12 months. In the diabetic group, the duration of years since the first diagnosis, the presence of neuropathy and the use of medication for diabetic management were documented through the subject's medical records.

\subsection{Physical Performances}

Timed-Up and Go test (TUG) was used for balance performance. The purpose is to measure mobility performance includes static and dynamic balance (Shumway-Cook, Brauer, \& Woollacott, 2000). The subjects were instructed to stand up from the chair, walk for 3 meters, turn and walked back to sit on the chair. The TUG test consists of three tasks. The time to complete the task was taken. Firstly, TUG-Single task is the regular walk for 3 meters. Secondly, the TUG-dual task needs the subject to carry a glass of water when performing TUG. Thirdly, TUG-Cognitive requires the subject to perform TUG while counting number backward. During the test, subjects should wear their regular footwear and use any mobility aid that they commonly used. It has been suggested that elderly with longer TUG durations are increasing their fall risk than those with shorter time (Kear, Guck, \& McGaha, 2017).

Modified Fall Efficacy Scale (mFES) is to measure the FOF. It is a self-reported questionnaire that assesses the level of concern about falls during daily activities. There are 14 simple activities at home in the questionnaire. A higher score shows more confidence, less FOF, while a lower score shows less confidence and high FOF. Each of the activity was rated with a 10-point scale of fear. The total scores are 140 and divided into ten ratings. Therefore, the scores $<8$ indicates high FOF, while a score of 8 or $>8$ means low fear (Hill, Schwarz, Kalogeropoulos, \& Gibson, 1996). 
The 30-second Chair Rise test (CRT) was used in the study to measure lower limb strength. The subjects were instructed to sit on a chair without armrest on flat ground and with arm folded across the chest. The subjects need to sit and stand up from the chair repeatedly within 30 seconds, while the researcher measures the number of seated down repetitions the subjects performed. Less number of repetitions indicate it reduced in lower limb strength (Contro et al., 2012).

\subsection{Results}

\subsection{Demographic details between diabetic and non-diabetic groups}

The result shows the demographic details between diabetic and non-diabetic in elderly. There are no significant differences in sex, marital status, level of education, the presence of hypertension, use of walking aids and history of falls $(p>.05)$. A summary of the results of each outcome measure can be seen in Table 1.

Table 1: Comparison of Demographic Details of Diabetic and Non-Diabetic Group $(n=80)$

\begin{tabular}{|c|c|c|c|c|c|c|}
\hline \multirow[t]{2}{*}{ Characteristics } & \multirow[t]{2}{*}{ Category } & \multicolumn{2}{|c|}{$\begin{array}{l}\text { Diabetic group } \\
(n=40)\end{array}$} & \multicolumn{2}{|c|}{$\begin{array}{l}\text { Non-diabetic } \\
\text { group }(n=40)\end{array}$} & \multirow[t]{2}{*}{$\begin{array}{l}P \\
\text { value }\end{array}$} \\
\hline & & $\mathrm{n}$ & $\%$ & $\mathrm{~N}$ & $\%$ & \\
\hline \multirow[t]{2}{*}{ Sex } & Male & 17 & 42.5 & 22 & 55.0 & .263 \\
\hline & Female & 23 & 57.5 & 18 & 45.0 & \\
\hline \multirow[t]{2}{*}{ Marital } & Married & 29 & 72.5 & 31 & 77.5 & .606 \\
\hline & Widowed & 11 & 27.5 & 9 & 22.5 & \\
\hline \multirow[t]{4}{*}{ Education } & No school & 10 & 25.0 & 6 & 15.0 & .417 \\
\hline & \multicolumn{6}{|l|}{ school } \\
\hline & $\begin{array}{l}\text { Secondary } \\
\text { school }\end{array}$ & 13 & 32.5 & 18 & 45.0 & \\
\hline & University & 3 & 7.5 & 1 & 2.5 & \\
\hline Use & Yes & 40 & 100 & 14 & 35.0 & $.000^{*}$ \\
\hline medication & No & 0 & 0 & 26 & 65.0 & \\
\hline Presence & Yes & 9 & 22.5 & 16 & 40.0 & .091 \\
\hline hypertension & No & 31 & 77.5 & 24 & 60.0 & \\
\hline \multirow[t]{2}{*}{ Health status } & Fair & 33 & 82.5 & 23 & 57.5 & $.015^{*}$ \\
\hline & Good & 7 & 17.5 & 17 & 42.5 & \\
\hline \multirow{2}{*}{$\begin{array}{l}\text { Use of walking } \\
\text { aids }\end{array}$} & Yes & 9 & 22.5 & 4 & 10.0 & .130 \\
\hline & No & 31 & 77.5 & 36 & 90.0 & \\
\hline \multirow[t]{2}{*}{ History of falls } & Yes & 14 & 35.0 & 9 & 22.5 & .217 \\
\hline & No & 26 & 65.0 & 31 & 77.5 & \\
\hline \multirow{2}{*}{$\begin{array}{l}\text { Presence of } \\
\text { FOF }\end{array}$} & Yes & 27 & 67.5 & 18 & 45.0 & $.043^{*}$ \\
\hline & No & 13 & 32.5 & 22 & 55.0 & \\
\hline \multirow{4}{*}{ Level of FOF } & Less & 2 & 5.0 & 16 & 40.0 & $.003^{*}$ \\
\hline & Normal & 19 & 47.5 & 12 & 30.0 & \\
\hline & Moderate & 14 & 35.0 & 9 & 22.5 & \\
\hline & Very & 5 & 12.5 & 3 & 7.5 & \\
\hline
\end{tabular}

Abbreviations: FOF= FOF, ${ }^{*} p$-value is significant when $<0.05$ 


\subsection{Physical performances between groups}

MFES is used to measure FOF as lower scores represent high FOF. The median score on the mFES in the diabetic group is $92.50( \pm 30)$, whereas the non-diabetic group is $107( \pm$ 48). Based on the result, mFES in the diabetic group was significantly compared to the nondiabetic group, $p=.001$. The result of lower limb strength showed that the diabetic group is $12( \pm 5)$, while the non-diabetic group is $14( \pm 5)$. However, there is no significant difference statistically in both groups, $p=.191$. The TUG-Single task result shows a median of $11.36( \pm$ $2.98)$ seconds in the diabetic group, while the non-diabetic group is $9.15( \pm 4.41)$ seconds. There was no significant difference between the two groups, $p=.075$. The TUG-Dual task took a longer time to complete compared to TUG-Single task because the elderly need to focus on two tasks. The median time to complete TUG-Dual task in the diabetic group is 24.49 ( \pm 19.81$)$ seconds, while the non-diabetic group is $24.79( \pm 20.11)$ seconds. The result showed that there is no significant difference between the two groups $(U=611.5, p=.070)$. In the diabetic group, the TUG-Cognitive task shows $12.97( \pm 3.40)$ seconds while the nondiabetic group is $10.29( \pm 5.16)$ seconds. There is no significant difference in TUG-Cognitive between the diabetic group and the non-diabetic group $(U=596.5, p=.050)$ (Table 2).

Table 2: Comparison of variables between Diabetic and Non-Diabetic Group.

\begin{tabular}{|c|c|c|c|c|c|}
\hline \multirow[t]{2}{*}{ Variables } & \multicolumn{2}{|c|}{ Diabetic group $(n=40)$} & \multicolumn{2}{|c|}{ Non-Diabetic group $(n=40)$} & \multirow{2}{*}{$\begin{array}{r}P \\
\text { value }\end{array}$} \\
\hline & Median & IQR & Median & IQR & \\
\hline Mfes & 92.50 & 30 & 107 & 48 & $0.001^{*}$ \\
\hline 30 Sec CRT & 12 & 5 & 14 & 5 & 0.191 \\
\hline $\begin{array}{l}\text { TUG-Single } \\
\text { task }\end{array}$ & 11.36 & 2.98 & 9.15 & 4.41 & 0.075 \\
\hline TUG-Dual task & 24.49 & 19.81 & 9.99 & 5.31 & $0.004^{*}$ \\
\hline TUG-Cognitive & 24.79 & 20.11 & 10.29 & 5.16 & $0.005^{*}$ \\
\hline
\end{tabular}

Abbreviations: $\mathrm{mFES}=$ modified falls efficacy scale, CRT=Chair rise test, $\mathrm{TUG}=$ time up-and-go test, ${ }^{*} \mathrm{p}$-value is significant when $<0.05$

\subsection{Discussion}

In this study, there was increased of FOF, reduce balance performance and lower limb weakness, especially in a cognitive task in the diabetic group as compared to the non-diabetic group. Previous studies revealed that peripheral neuropathy and FOF are related to gait performance (Kelly et al., 2013; Moreira et al., 2017). As blood glucose level increase, the biochemical abnormalities will cause changes in protein glycation and elevate the level of reactive oxygen species, so this will lead to vascular damage (Paneni, Beckman, Creager \& Cosentino, 2013) and impaired somatosensory system (Giacco \& Brownlee, 2010). This may result in a lack of sensation and further, reduce the gait performance and increase FOF. 
However, a study by Kelly et al. (2013) revealed that the FOF and DPN did not show correlation. In contrast, there is a strong correlation between the history of falls and FOF (Chang, Chen, \& Chou, 2016; Lee, 2013). Throughout this study, $28.8 \%$ of elderly acknowledged experiencing several histories of falls. History of falls which are affecting leg strength, functional task, and FOF. (Ambrose, Paul, \& Hausdorff, 2013; Chang et al., 2016; Kenny, Romero-Ortuno, \& Kumar, 2017; Moreira et al., 2017). Multiple histories of falls will have a psychological problem.

The elderly population who had increased FOF will also have poor balance performance (Gazzolaa, Perracini, Ganançac \& Ganançad, 2006). The previous study showed that there is a link between FOF and balance performance among elderly (Ambrose et al., 2013; Dionyssiotis, 2012; Reelick et al., 2009). The FOF will develop anxiety among the elderly and affect the attentional processes that require to maintain balance performance. This changes will alter the motor control and resulting in poor balance performance (Young \& Mark Williams, 2015). Based on our study, the mFES result was correlated with the TUG test. Therefore, this finding supports other studies.

Several studies revealed that elderly with diabetic associate with reducing muscle strength as compared to the non-diabetic group (Leenders et al., 2013; Seok Won Park, Goodpaster, Strotmeyer). However, the result of chair rise test is non-significant as the diabetic people may have reduced muscle strength (Leenders et al., 2013). This is because the subjects were not severe and fewer complications. Previous studies demonstrated that loss of muscle mass and strength in diabetic people was higher with long-term and more severe diabetes (Van Sloten et al., 2011).

Furthermore, long term diabetes with various complications is correlated with reduce quadriceps strength in the elderly population (Kalyani et al., 2013). A study by IJzerman et al., (2012) showed that the development of insulin resistance in diabetic people causes irregularities in lower limb muscle metabolism. It is approximately $30 \%$ to $50 \%$ muscle strength reduce for the lower limb caused by the effect of insulin resistance. Studies by Morcelli et al., (2016) and Power et al., (2013) stated that reduce in muscles power and torque rate, and decrease muscle initiation is due to morphological changes in the muscles itself.

In advancing age, there is a decline in leg strength, poor balance performance and increased FOF which lead to high risk of falls (Pinheiro et al., 2014; Toebes et al., 2015) and reduce quality of life (IJzerman et al., 2012; Seok Won Park, Goodpaster, Strotmeyer, de Rekeneire, et al., 2006). People with frequent histories of falls are related to poor leg strength. Experiencing falls will lead to poor balance performance (Hewston \& Deshpande, 2016) and loss of muscle strength (Moreira et al., 2017; Tander et al., 2016). The current study shows that diabetic elderly took a longer time to complete the TUG task. A previous study by Chiba et al. (2015), support that poor glycaemic and psychological status may lead to poor balance performance which increases the risk of falls and FOF. A study by Hasting and colleagues (2015) stated that foot deformity and neuropathy could lead to the change of foot posture, resulting in poor balance and gait, thus, decrease walking velocity (MacGilchrist et al., 2010). It is believed that more severe diabetes, the more challenging it was to complete the task.

Reduce mobility among the elderly with lower functional ability are more anxious about 
falling. It is known that the fear of fall leads to functional decline (Young \& Mark Williams, 2015). Thus, the elderly with FOF can cause them to reduce their activity in the study. Previous studies supported that decrease functional mobility in daily activities is associated with reduced muscle strength either in the diabetic or non-diabetic group (De Villiers \& Kalula, 2015; Leenders et al., 2013; Schaap, Koster, \& Visser, 2013).

Diabetes may reduce muscle strength due to weak balance impact. It was reported by Alvarenga, Pereira, \& Anjos (2010) that, diabetes is associated with a decline in the TUGDual task. In contrast, there is no significant difference between both groups in the current study because the subjects in the study are having non-severe and fewer complications. The previous research by Sertel and colleagues (2017) reported that decrease performance among diabetes group is caused by the concentration required by the elderly to complete dual-task. The capacity theory proposed that when an individual performing dual-tasks there is competition for information processing, which can result in a reduction of performance in one or both tasks (Kelly et al., 2013). TUG-Cognitive task poses a challenge to attentional abilities by elderly where the central mechanism which the prefrontal cortex activity and executive functions are influenced (Al-Yahya et al., 2011). Similarly, the previous study showed that there is a significant difference between both groups, where elderly diabetic showed reduce performance and took more extended time in completing the task (Alvarenga et al., 2010; Rucker et al., 2014; Sertel et al., 2017).

Additionally, this study revealed high cognitive impairment in diabetic elderly as compared to non-diabetic. The cognitive decline was due to longer duration since diagnosis of diabetes and poor glycaemic control. Kim \& Feldman (2012) found that insulin regulates neurons in the central nervous system. Numerous studies revealed the roles of diabetes in affecting cognitive status might lead to a slower gait, delayed performance and increase the risk of falls (Roman de Mettelinge, Cambier, Calders, Van Den Noortgate, \& Delbaere, 2013; Sims-Robinson, Kim, \& Feldman, 2014). Throughout the study, the performance of balance and lower limb strength is influenced by cognitive status. Yogev- Seligmann, Hausdorff, \& Giladi (2008) reported that performance of walking depends on cognitive converting, executive functions and consideration of individuals. Since cognitive status and diabetes are correlated with FOF, balance performance and muscle strength, this study proposes that diabetic elderly with a cognitive impairment may likely to have balance disturbances, weak muscle strength, increase fear, and fall risk. Long-term hyperglycemia will increase oxidative stress that can damage neurons leading to cognitive impairment (Giacco \& Brownlee, 2010). Al-Yahya and colleagues (2011) also showed that gait performance with cognitive task requires greater attention ability especially in diabetic elderly.

Elderly who experienced a fall will develop a behavior where they believe after suffering one fall; there will be the risk of having another fall. Thus, lead to a cyclical effect of falls, FOF, reduce functional performance, poor muscle strength, and poor health status. Additionally, trauma can lead to low self-efficacy among elderly (Simmen-Janevska, Brandstätter \& Maercker, 2012) and self-confidence because they believed that avoidance of functional activities acts as falls prevention. Hence, the cycle needs to prevent to maintain the health status, improve useful independent and avoid any other consequences related to falls in the future. 
The limitation of this study is lack evaluation of mental status among subjects. Only cognitive status was evaluated. In this study, the presence of diabetes was only assessed through self-report or by last medical check-up at the hospital. The severity of diabetes is based on glucose concentration in the body. The subjects in this study mostly have a higher socioeconomic background where they have a better total diet quality and partaking in regular exercise. Therefore, the difference was seen between the diabetic and non-diabetic group regarding the balance performance for all tasks.

\subsection{Conclusion}

In this study, it was showed that the elderly with diabetes had a high incidence of FOF, balance impairment and reduced lower limb strength compared to the non-diabetic group. All of the parameters such as age, duration since diagnosis, history of falls, DPN, level of fear, balance performance and lower limb strength showed a significant association with fear of fall in a diabetic. Also, the completion time for the TUG task in diabetic group was significantly correlated with FOF and lower limb strength. Meanwhile, reduce in muscle strength is reported to lessen balance performance and increased FOF in both groups. Based on the results of this study, the cognitive status of diabetic elderly showed a significant positive correlation with FOF, lower limb strength, and balance performance.

It is recommended for future research to gather more participants and compare between genders as it can help to identify the gender difference in Malaysian population too. It is also recommended to involve other races, nationalities and institutional level with diabetic elderly as the subjects which to determine their risk of fall and compare between community and institutional. The health care professionals, especially physiotherapists, are encouraged the elderly with diabetic to participate in a healthy lifestyle which includes a suitable exercise program to improve their overall quality of life. In the future, combined exercise program and cognitive behavioral therapy are required in managing people with high FOF and impaired cognitive status to improve physical and mental condition among the elderly population.

\section{Acknowledgment}

This project was made possible by grants from the Research Management Institute (600RMI/DANA 5/3/LESTARI [0095/2016]), Universiti Teknologi MARA, Selangor, Malaysia.

\section{References}

Bishop, K., \& Said, I., (2017). Challenges of Participatory Qualitative Research in a Malaysian and Australian Hospital. Asian Journal of Environment-Behaviour Studies, 2(4), 1-11.

Collado, S., \& Corraliza, J., A. (2017). Children's Perceived Restoration and Pro-Environmental Beliefs. Journal of ASIAN Behavioural Studies, 2(2), 1-12.

Fachinger, J., den Exter, M., Grambow, B., Holgerson, S., Landesmann, C., Titov, M., et al. (2004). Behavior of 
spent HTR fuel elements in aquatic phases of repository host rock formations, 2nd International Topical Meeting on High Temperature Reactor Technology. Beijing, China, paper \#B08.

Mehdi K., \& Koorosh, A. (2015). Achievement to Environmental Components of Educational Spaces for Iranian Trainable Children with Intellectual Disability. Procedia - Social and Behavioral Sciences, 201, 9-18.

Mettam, G. R., \& Adams, L. B. (1999). How to prepare an electronic version of your article. In B. S. Jones \& R. Z. Smith (Eds.), Introduction to the electronic age (pp. 281-304). New York: E-Publishing Inc.

Adolphs, R. (2013). The biology of fear. Current Biology, 23(2), R79-R93.

Afridi, A. (2015). Relationship between fear, fall \& balance in community dwelling older adults relationship between fear, Fall \& Balance In, 10(2).

Al-Yahya, E., Dawes, H., Smith, L., Dennis, A., Howells, K., \& Cockburn, J. (2011). Cognitive motor interference while walking: A systematic review and meta-analysis. Neuroscience and Biobehavioral Reviews.

Alvarenga, P. P., Pereira, D. S., \& Anjos, D. M. C. (2010). Mobilidade funcional e função executiva em idosos diabéticos e não diabéticos. Brazilian Journal of PhysicalTherapy, 14(6), 491-496.

Ambrose, A. F., Paul, G., \& Hausdorff, J. M. (2013). Risk factors for falls among older adults: A review of the literature. Maturitas, 75(1), 51-61.

Chang, H.-T., Chen, H.-C., \& Chou, P. (2016). Factors Associated with Fear of Falling among Community-Dwelling Older Adults in the Shih-Pai Study in Taiwan. PLOS ONE, 11(3), e0150612.

Chiba, Y., Kimbara, Y., Kodera, R., Tsuboi, Y., Sato, K., Tamura, Y., ... Araki, A. (2015). Risk factors associated with falls in elderly patients with type 2 diabetes. Journal

of Diabetes and lts Complications, 29(7), 898-902.

Contro, N. C. for I. P. and, Protocol, H. C., Oliver, D., Daly, F., Martin, F. C., McMurdo, M. E. T., ... Marra, C. a. (2012). The 30-Second Chair Stand Test. Age and Ageing,

33(5), 1952-1960.

Cukierman, T., Gerstein, H. C., \& Williamson, J. D. (2005). Cognitive decline and dementia in diabetes Systematic overview of prospective observational studies.

Diabetologia.

De Villiers, L., \& Kalula, S. Z. (2015). An approach to balance problems and falls in elderly persons - south African Medical Journal, 105(8), 695.

Dionyssiotis, Y. (2012a). Analyzing the problem of falls among older people. International Journal of General Medicine.

Dionyssiotis, Y. (2012b). Analyzing the problem of falls among older people. International Journal of General Medicine, 5, 805-813.

Ghanavati, T., Shaterzadeh Yazdi, M. J., Goharpey, S., \& Arastoo, A. A. (2012). Functional balance in elderly with diabetic neuropathy. Diabetes Research and ClinicalPractice, 96(1), 24-28.

Giacco, F., \& Brownlee, M. (2010). Oxidative Stress and Diabetic Complications. Circulation Research, 107(9), 1058-1070.

Hastings, M. K., Mueller, M. J., Woodburn, J., Strube, M. J., Commean, P., Johnson, J. E., Cheuy, V., ... Sinacore, D. R. (2015). Acquired midfoot deformity and function 
in individuals with diabetes and peripheral neuropathy. Clinical biomechanics (Bristol, Avon), 32, 261-7.

Hewston, P., \& Deshpande, N. (2016). Falls and Balance Impairments in Older Adults with Type 2 Diabetes: Thinking Beyond Diabetic Peripheral Neuropathy. Canadian

Journal of Diabetes, 40(1), 6-9.

Hewston, P., \& Deshpande, N. (2018). Fear of Falling and Balance Confidence in Older Adults with Type 2 Diabetes Mellitus: a Scoping Review. Canadian Journal of

Diabetes.

Hill, K. D., Schwarz, J. A., Kalogeropoulos, A. J., \& Gibson, S. J. (1996). Fear of falling revisited. Archives of Physical Medicine and Rehabilitation, 77(10), 1025-1029.

IJzerman, T. H., Schaper, N. C., Melai, T., Meijer, K., Willems, P. J. B., \& Savelberg, H. H. C. M. (2012). Lower extremity muscle strength is reduced in people with type 2 diabetes, with and without polyneuropathy, and is associated with impaired mobility and reduced quality of life. Diabetes Research and Clinical Practice, 95(3), 345351.

Jung, D. (2008). Fear of Falling in Older Adults: Comprehensive Review. Asian Nursing Research, 2(4), 214-222.

Kalyani, R. R., Tra, Y., Yeh, H. C., Egan, J. M., Ferrucci, L., \& Brancati, F. L. (2013). Quadriceps strength, quadriceps power, and gait speed in older U.S. adults with

diabetes mellitus: results from the National Health and Nutrition Examination Survey, 1999-2002. Journal of the American Geriatrics Society, 61(5), 769-775.

Kear, B. M., Guck, T. P., \& McGaha, A. L. (2017). Timed Up and Go (TUG) Test. Journal of Primary Care \& Community Health, 8(1), 9-13.

Kelly, C., Fleischer, A., Yalla, S., Grewal, G. S., Albright, R., Berns, D., ... Najafi, B. (2013). Fear of falling is prevalent in older adults with diabetes mellitus but is unrelated

to level of neuropathy. Journal of the American Podiatric Medical Association, 103(6), 480-488.

Kenny, R. A., Romero-Ortuno, R., \& Kumar, P. (2017). Falls in older adults. Medicine (United Kingdom), 45(1), 28 33.

Kim, B., \& Feldman, E. L. (2012). Insulin resistance in the nervous system. Trends in Endocrinology and Metabolism.

Kirkman, M. S., Briscoe, V. J., Clark, N., Florez, H., Haas, L. B., Halter, J. B., ... Swift, C. S. (2012). Diabetes in older adults. Diabetes Care, 35(12), 2650-2664.

Kumar, A., Carpenter, H., Morris, R., lliffe, S., \& Kendrick, D. (2014). Which factors are associated with fear of falling in community-dwelling older people? Age and Ageing, 43(1), 76-84.

Lavedán, A., Viladrosa, M., Jürschik, P., Botigué, T., Nuín, C., Masot, O., \& Lavedán, R. (2018). Fear of falling in community-dwelling older adults: A cause of falls, a consequence, or both? PLOS ONE, 13(3), e0194967.

Lee, A. (2013). Preventing Falls in the Geriatric Population. The Permanente Journal, 17(4), 37-39.

Leenders, M., Verdijk, L. B., van der Hoeven, L., Adam, J. J., van Kranenburg, J., Nilwik, R., \& Van Loon, L. J. C. (2013). Patients with type 2 diabetes show a greater decline in muscle mass, muscle strength, and functional capacity with aging. Journal of the American Medical Directors Association, 14(8), 585-592.

Lim, K. B., Kim, D. J., Noh, J. hyun, Yoo, J., \& Moon, J. W. (2014). Comparison of balance ability between patients with type 2 diabetes and with and without peripheral neuropathy. PM and R, 6(3), 209-214. 
MacGilchrist, C., Paul, L., Ellis, B. M., Howe, T. E., Kennon, B., \& Godwin, J. (2010). Lower-limb risk factors for falls in people with diabetes mellitus. Diabetic Medicine, 27(2), 162-168.

Malini, F. M., Lourenço, R. A., \& Lopes, C. S. (2016). Prevalence of fear of falling in older adults, and its associations with clinical, functional and psychosocial factors: The Frailty in Brazilian Older People-Rio de Janeiro Study. Geriatrics \& Gerontology International, 16(3), 336-344.

Morcelli, M. H., LaRoche, D. P., Crozara, L. F., Marques, N. R., Hallal, C. Z., Rossi, D. M., ... Navega, M. T. (2016). Neuromuscular performance in the hip joint of elderly fallers and non-fallers. Aging Clinical and Experimental Research, 28(3), 443-450.

Moreira, B. de S., Sampaio, R. F., Diz, J. B. M., Bastone, A. de C., Ferriolli, E., Neri, A. L., ... Kirkwood, R. N. (2017). Factors associated with fear of falling in communitydwelling older adults with and without diabetes mellitus: Findings from the Frailty in Brazilian Older People Study (FIBRA-BR). Experimental Gerontology, 89, 103-111.

Nisar, M. U., Asad, A., Waqas, A., Ali, N., Nisar, A., Qayyum, M. A., Maryam, H., Javaid, M., ... Jamil, M. (2015). Association of Diabetic Neuropathy with Duration of Type 2 Diabetes and Glycemic Control. Cureus, 7(8), e302. P, S., \& S, G. (2017). Association between Physical Functioning and Fear of Falling with Balance in Elderly Diabetic Individuals. Journal of Physiotherapy \& Physical Rehabilitation, 2(3).

Paneni, F., Beckman, J. A., Creager, M. A., \& Cosentino, F. (2013). Diabetes and vascular disease: pathophysiology, clinical consequences, and medical therapy: part I. European heart journal, 34(31), 2436-43.

Papa, E. V., Dong, X., \& Hassan, M. (2017). Skeletal Muscle Function Deficits in the Elderly: Current Perspectives on Resistance Training. Journal of Nature and Science, 3(1), e272.

Park, S. W., Goodpaster, B. H., Strotmeyer, E. S., De Rekeneire, N., Harris, T. B., Schwartz, A. V., ... Newman, A. B. (2006). Decreased muscle strength and quality in older adults with type 2 diabetes: The health, aging, and body composition study. Diabetes, 55(6), 1813-1818.

Pinheiro, H. A., Vilaça, K. H. C., \& Carvalho, G. de A. (2014). Postural stability, risk of falls and fear of falling in elderly with diabetic neuropathy who do therapeutic exercises. Fisioterapia E Pesquisa, 21(2), 127-132.

Power, G. A., Dalton, B. H., \& Rice, C. L. (2013). Human neuromuscular structure and function in old age: A brief review. Journal of Sport and Health Science.

Reelick, M. F., van lersel, M. B., Kessels, R. P. C., \& Olde Rikkert, M. G. M. (2009). The influence of fear of falling on gait and balance in older people. Age and Ageing, 38(4), 435-440.

Roman de Mettelinge, T., Cambier, D., Calders, P., Van Den Noortgate, N., \& Delbaere, K. (2013). Understanding the Relationship between Type 2 Diabetes Mellitus and Falls in Older Adults: A Prospective Cohort Study. PLoS ONE, 8(6), e67055.

Rucker, J. L., Jernigan, S. D., McDowd, J. M., \& Kluding, P. M. (2014). Adults with diabetic peripheral neuropathy exhibit impairments in multitasking and other executive functions. Journal of Neurologic Physical Therapy : JNPT, 38(2), 104-110.

Schaap, L. A., Koster, A., \& Visser, M. (2013). Adiposity, muscle mass, and muscle strength in relation to functional decline in older persons. Epidemiologic Reviews, 35(1), 51-65.

Schinkel-Ivy, A., Inness, E. L., \& Mansfield, A. (2015). Relationships between fear of falling, balance confidence, and control of balance, gait, and reactive stepping in individuals with sub-acute stroke. Gait \& posture, 43, 154-9. 
Sertel, M., Sakızlı, E., Bezgin, S., Savcun Demirci, C., Yıldırım Şahan, T., \& Kurtoğlu, F. (2017). The effect of singletasks and dual-tasks on balance in older adults. Cogent Social Sciences, 3(1).

Shumway-Cook, Brauer, S., \& Woollacott, M. (2000). Timed Up \& Go Test (TUG). Missouri.Edu, 80(1991), 9-10. Sims-Robinson, C., Kim, B., \& Feldman, E. L. (2014). Diabetes and Cognitive Dysfunction. In Neurobiology of Brain Disorders: Biological Basis of Neurological and Psychiatric Disorders (pp. 189-201).

Singh, A., \& Misra, N. (2009). Loneliness, depression and sociability in old age. Industrial Psychiatry Journal, 18(1), $51-55$.

Tander, B., Atmaca, A., Ulus, Y., Tura, Ç., Akyol, Y., \& Kuru, Ö. (2016). Diyabetli yaşlılarda denge ve düşme korkusu: Diyabetli olmayan yaşlıarla karşılaşıırmalı bir çalışma. Turkiye Fiziksel Tip ve Rehabilitasyon Dergisi, 62(4), 314322.

Tee, E.-S., \& Yap, R. W. K. (2017). Type 2 diabetes mellitus in Malaysia: current trends and risk factors. European Journal of Clinical Nutrition, 71(7), 844-849.

Thiamwong, L., \& Suwanno, J. (2017). Fear of Falling and Related Factors in a Community-based Study of People 60 Years and Older in Thailand. International Journal of Gerontology, 11(2), 80-84.

Tilling, L. M., Darawil, K., \& Britton, M. (2006). Falls as a complication of diabetes mellitus in older people. Journal of Diabetes and Its Complications, 20(3), 158-162.

Timar, B., Timar, R., Gai????, L., Oancea, C., Levai, C., \& Lungeanu, D. (2016). The Impact of Diabetic Neuropathy on Balance and on the Risk of Falls in Patients with Type 2 Diabetes Mellitus: A Cross-Sectional Study. PloS One, 11(4), e0154654.

Toebes, M. J. P., Hoozemans, M. J. M., Furrer, R., Dekker, J., \& Van Dieën, J. H. (2015). Associations between measures of gait stability, leg strength and fear of falling. Gait and Posture, 41(1), 76-80.

Van Sloten, T. T., Savelberg, H. H. C. M., Duimel-Peeters, I. G. P., Meijer, K., Henry, R. M. A., Stehouwer, C. D. A., \& Schaper, N. C. (2011). Peripheral neuropathy, decreased muscle strength and obesity are strongly associated with walking in persons with type 2 diabetes without manifest mobility limitations. Diabetes Research and Clinical Practice, 91(1), 32-39

Vinik, A. I., Vinik, E. J., Colberg, S. R., \& Morrison, S. (2015). Falls Risk in Older Adults with Type 2 Diabetes. Clinics in Geriatric Medicine, 31(1), 89-99.

Yeong, U. Y., Tan, S. Y., Yap, J. F., \& Choo, W. Y. (2016). Prevalence of falls among community-dwelling elderly and its associated factors: A cross-sectional study in Perak, Malaysia. Malaysian Family Physician, 11(1), 7-14.

Yogev-Seligmann, G., Hausdorff, J. M., \& Giladi, N. (2008). The role of executive function and attention in gait. Movement Disorders.

Young, W. R., \& Mark Williams, A. (2015). How fear of falling can increase fall-risk in older adults: Applying psychological theory to practical observations. Gait \& Posture, 41(1), 7-12. 